\title{
Experimental Study on the Effect of the Geometry of Punching Tool on Clinch Joints
}

\author{
SZ. JóNÁS' ${ }^{1}$ P. Z. KovÁCS² \\ University of Miskolc, Institute of Materials Sciences and Technology, Department of Mechanical Technology \\ szabolcs.jonas@gmail.com¹, metkpz @uni-miskolc.hu²
}

Abstract. In this study the effect of the punching tool's geometry on aluminum alloy clinch joints is analyzed by experiments. Based on FE simulations the tip radius and the cone angle of the punching tool is changed, and their effect was analyzed by microscopic investigations and single lap tensile-shear tests.

\section{Introduction}

In this study the effect of the punching tool's geometry on the geometry and the strength is investigated by experiments. The original punch was developed for DP 600 type of steel, but in this article, we used AA6082 aluminum alloy.

The clinch joints are mechanical joining by local plastic forming technique between similar or dissimilar usually thin sheets with variable thicknesses. The cross section of a clinched joint can be seen in Figure 1. The joining technique is widely used by the automotive industry as a fast, costeffective and eco-friendly method in place of spot welded or self-piercing riveted joints [1].

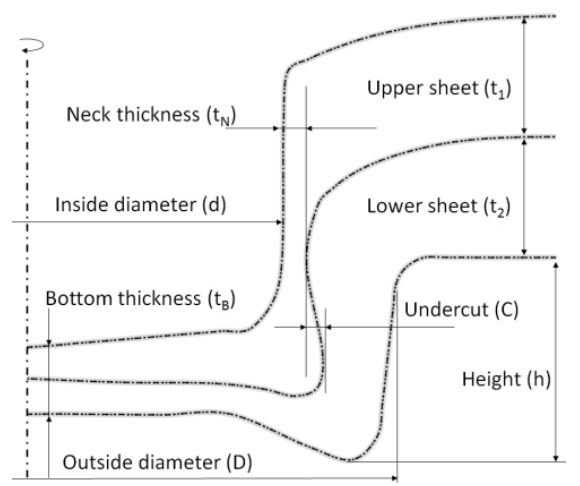

Figure 1. Cross section and main geometrical parameters of a round clinch joints.

Nowadays several researchers deal with the optimization of clinching tools because of the increasing interest. The goal is the make better joints. The geometry of the clinching tool has an impact as it can be read in the following works [2][3][4]. Different approaches were used to determine the proper tools e.g. experiments, FEA, neural networks, etc. The clinching tool basically contains three parts which are the punch, the die and the blank holder. All of them has an impact on the final geometry from which strength of the joints directly depends on. 


\section{Experiments with dissimilar tools}

The tool geometry effect was examined by five different tools. The material of the joined sheets was AA6082 aluminum alloy. The originally developed tool (signed by \#0) is a TOX product with unknown material properties and heat treatment and developed for DP600 steels with the bottom thickness of $0.5 \mathrm{~mm}$ (Figure 2.). To avoid the compression of the tools during clinch joint formation the expected bottom thickness was $0.75 \mathrm{~mm}$. The new four (\#2-\#5) tools were made M1 type of steel and had a heat treatment after machining of quenching and tempering.

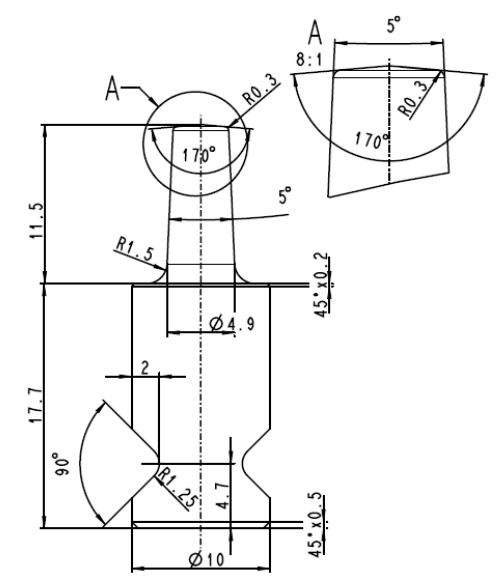

Figure 2. Punching tool's geometry.

The modified parameters were the tip radius (originally $\mathrm{R}=0.3 \mathrm{~mm}$ ) and the angle of the conical part of tool (originally $\alpha=5^{\circ}$ ), which parameters are depicted on the detailed drawing based on previous FE studies. The Table 1. contains all the variants of the tools which were produced for the experiments.

\begin{tabular}{|c|c|c|}
\hline & Radius $[\mathrm{mm}]$ & Angle $\left[^{\circ}\right]$ \\
\hline$\# 0$ & 0.3 & 5 \\
\hline$\# 2$ & 0.3 & 8 \\
\hline$\# 3$ & 0.3 & 2 \\
\hline$\# 4$ & 0.5 & 5 \\
\hline$\# 5$ & 0.1 & 5 \\
\hline
\end{tabular}

Table 1. Punching tools with different geometry.

As it can be seen all the variants only taken into consideration one parameter change in one tool.

\section{Evaluation of the joints}

With every variants of tools made a joint to microscopic investigation. The geometrical parameters of cross sections were measured based on the macro photographs according to the Figure 3. 


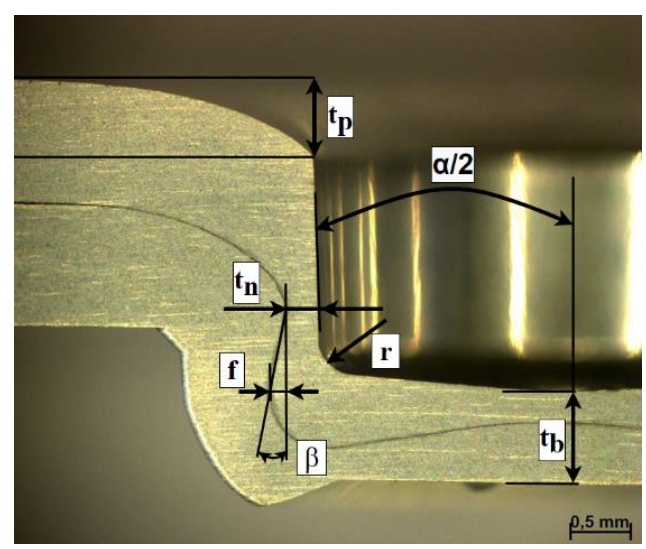

Figure 3. Measured parameters.

The measured values can be seen in Table 2. The neck thickness and the undercut values show interesting variation. Figure 4. shows the relationship between the undercut and neck thickness values. The two values are behaving of the opposite to each other. When the highest is the neck thickness, the undercut is the lowest one. The optimal case when both parameters are the highest. The tensile shear strength of the joints is depending on the neck thickness. As it can be seen the \#3 joint has the highest neck thickness and provide the highest tensile-shear strength according to the tensileshear measurements (Figure 6), however the value of the undercut is the lowest for these joints, the undercut is affect the pull out strength of the joints.

\begin{tabular}{|c|c|c|c|c|c|c|}
\hline & $\alpha\left[^{\circ}\right]$ & $\mathrm{f}[\mathrm{mm}]$ & $\mathrm{t}_{\mathrm{n}}[\mathrm{mm}]$ & $\mathrm{r}[\mathrm{mm}]$ & $\beta\left[^{\circ}\right]$ & $\mathrm{t}_{\mathrm{p}}[\mathrm{mm}]$ \\
\hline$\# 0$ & 2.41 & 0.16 & 0.28 & 0.30 & 11.34 & 0.61 \\
\hline$\# 2$ & 2.49 & 0.14 & 0.30 & 0.22 & 11.18 & 0.63 \\
\hline$\# 3$ & 2.46 & 0.10 & 0.36 & 0.41 & 8.00 & 0.65 \\
\hline$\# 4$ & 0.85 & 0.13 & 0.26 & 0.29 & 11.17 & 0.66 \\
\hline$\# 5$ & 4.07 & 0.10 & 0.32 & 0.30 & 7.12 & 0.63 \\
\hline
\end{tabular}

Table 2. Measure geometrical parameters.

The tensile-shear tests are performed on the MTS electro-hydraulic material testing machine with a special gripping equipment. The same machine was used to make the joints with the equipped TOX clinching tool.

The specimens of the tests are single lap joints with a $30 \mathrm{~mm}$ overlap. The size of the sheets was $100 \times 30 \times 1 \mathrm{~mm}^{3}$.

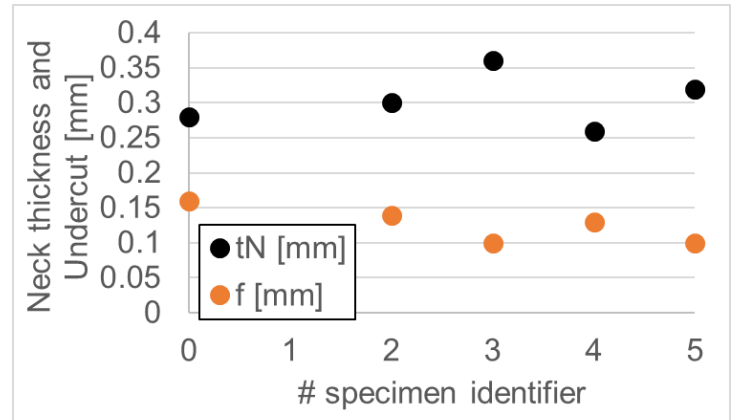

Figure 4. Cross section of the joints prepared with different tools. 

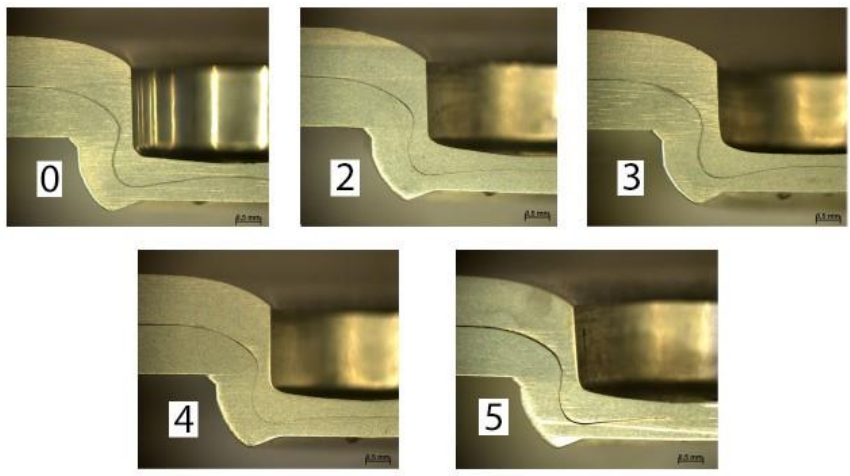

Figure 5. Cross section of the joints prepared with different tools.

Figure 5 shows the different joints with the different tools. The averaged tensile-shear curves of the tests can be seen in Figure 6. The red colored curve $(\# 0)$ is the results of the original tool. The increasing radius (\#4) shows a similar strength. The smaller angle (\#3) and smaller the smaller radius (\#5) show definitely higher forces. According to the box plots (Figure 7.) of the test results the joints with \#3 tool are much better than the original and has a small scatter on the maximal loads. The maximal loads with tool \#5 also higher, but the scatter of the results is also.

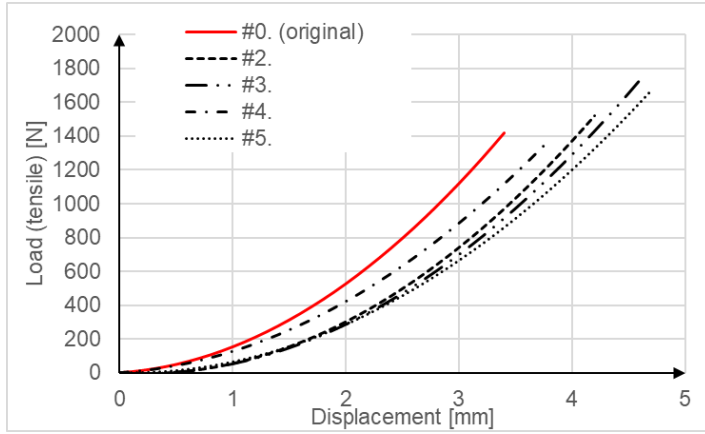

Figure 6. Averaged tensile-shear curves.

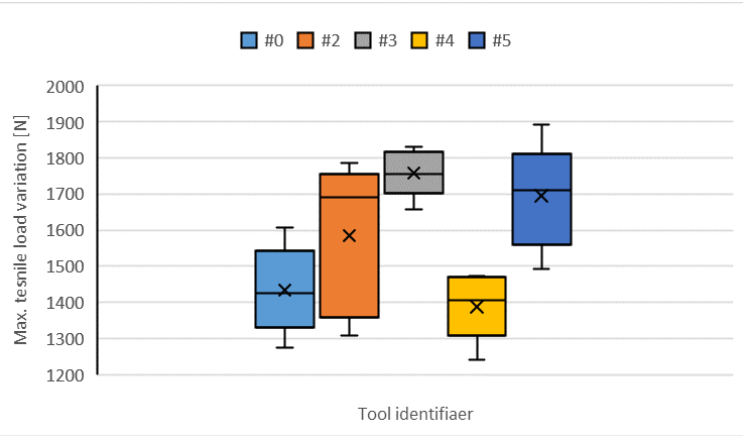

Figure 7. Box plots of the tests.

The tool \#2 shows varying results which indicates that the reproducibility of joints with high angles is problematic which leads to unreliable joints.

\section{Results and future work}

The different tools were compared and found that the smaller angle provides better joints, because the neck thickness is getting bigger and the bigger radius provides unreliable joints. From the measured parameters it can be deduced that the improved neck thickness shows opposite undercut. To improve the joint strength the experimental tests are necessary, however the cost of the tests is high and often problematic to perform the appropriate ones. In the future the authors would like to make FE simulation which take consider the cross-effects of the parameters (e.g. the change of the radius and the angle at the same time). 


\section{Acknowledgement}

Supported by the ÚNKP-19-3 New National Excellence Program of the Ministry for Innovation and Technology.

This research was supported by the European Union and the Hungarian State. co-financed by the European Regional Development Fund in the framework of the GINOP-2.3.4-15-2016-00004 project. aimed to promote the cooperation between the higher education and the industry.

\section{References}

[1] Sz. Jónás. M. Tisza (2018). Numerical investigation of clinched joints. Materials Science and Engineer. vol. 39/2. pp. 65-74.

[2] F. Lambiase. A. Di Ilio (2013). Optimization of the clinching tools by means of integrated FE modelling and artificial intelligence techniques. Procedia CIRP 12. pp.163-168.

[3] F. Lambiase. A. Di Ilio (2014). An experimental study on clinched joints realized with different dies. Thin-Walled Structures 85

[4] S. Lee. C. Lee. J. Lee. B. Kim. D. Ko (2015). Influence of Tool Shape on Hole Clinching for Carbo Fiber-Reinforced Plastic and SPRC440. Advances in Mechanical Engineering 